\title{
Perancangan Sistem Informasi Praktek Kerja Industri di SMK Bakti Nusantara 666 Cileunyi
}

\author{
Mochamad Baiduri ${ }^{1}$, Erna Susilawati $^{2}$ \\ 1,2Program Studi Sistem Informasi, Universitas Komputer Indonesia, Bandung, Indonesia \\ e-mail: 1'mbaiduri15@gmail.com, 2ernasusilawati@email.unikom.ac.id
}

\begin{abstract}
Abstrak
SMK Bakti Nusantara 666 yaitu sebuah sekolah menengah kejuruan yang terletak di Kab. Bandung. Pada tahun ajaran 2016/2017, SMK Bakti Nusantara 666 memiliki siswa kelas 11 sebanyak 485 siswa dari 5 jurusan. Dengan jumlah siswa prakerin yang banyak bagian hubin akan mengolah siswa tersebut. Banyaknya jumlah siswa dengan sistem prakerin yang masih dilakukan secara manual rawan akan keterlambatan penyelesaian pekerjaan dan tumpukan dokumen. Dalam hal ini SMK Bakti Nusantara 666 belum memiliki sistem informasi yang dapat mempermudah pendaftaran, agenda harian monitoring, dan penilaian prakerin. Oleh karena itu, perlu dirancang suatu sistem informasi yang bisa membantu proses prakerin, yaitu dalam hal pendaftaran, agenda harian monitoring, dan penilaian prakerin. Metode penelitian yang digunakan adalah metode deskriptif. Metode pendekatan sistem yang diaplikasi adalah metode terstruktur dan metode pengembangan menggunakan metode waterfall. Perancangan sistem informasi praktek kerja industri dapat membantu siswa, bagian hubin dan penguji prakerin dalam ketiga proses tersebut, yaitu dengan dapat mengakses sistem dimanapun dan kapanpun. Selain itu, keterlambatan pengolahan data nilai prakerin dan tumpukan dokumen dapat diminimalisir.
\end{abstract}

Kata kunci: Sistem Informasi, Prakerin, SMK Bakti Nusantara 666

\begin{abstract}
SMK Bakti Nusantara 666 is a vocational high school located in Kab. Bandung. In the 2016/2017 school year, SMK Bakti Nusantara 666 had 485 grade 11 students from 5 majors. With the large number of students in the internship section it will process these students. The large number of students with the manual labor system that is still done manually is prone to delays in completing work and piles of documents. In this case SMK Bakti Nusantara 666 does not yet have an information system that can facilitate registration, daily monitoring agenda, and apprenticeship assessment. Therefore, it is necessary to design an information system that can help the internal engineering process, namely in terms of registration, daily agenda of monitoring, and appraisal assessment. The method used is descriptive method. The system approach method applied is a structured method and a development method using the waterfall method. The design of the apprenticeship information system can help students, the hubin and the internship testers in the three processes, namely by being able to access the system wherever and whenever. In addition, delays in processing the prakerin and stack documents can be minimized.
\end{abstract}

Keywords: Information System, Prakerin, SMK Bakti Nusantara 666

\section{Pendahuluan}

Pada perkembangan zaman sekarang, teknologi semakin berkembang karena selalu ada inovasi baru untuk mengikuti kebutuhan manusia tersebut, terutama pada era 
globalisasi seperti saat ini yang sangat menuntut kita semua mengikuti perkembangan teknologi yang tepat guna supaya tidak ketinggalan zaman. Oleh sebab itu, manusia menjadi sangat bergantung pada teknologi terutama teknologi komputer.

SMK Bakti Nusantara 666 terdapat praktek kerja industry (prakerin). Manajemen prakerin meliputi proses pendaftaran prakerin, penempatan dan penilaian prakerin. Ketiga proses tersebut masih menggunakan cara manual sehingga memperlambat dalam pendataan peserta prakerin dan pencarian data siswa peserta prakerin. Hal ini, dikarenakan banyaknya jumlah siswa yang mencapai 485 siswa.

Pendaftaran dimulai dari surat rekomendasi wali kelas dan melampirkan raport semester 1 dan 2 tuntas sebagai syarat prakerin kepada guru bagian hubin. Pemilihan tempat prakerin masih menggunakan cara manual mengisi formulir. Dengan proses pendaftaran dan pemilihan tempat seperti itu, proses pembuatan surat pengajuan dan informasi diterima atau ditolaknya oleh perusahaan siswa prakerin mengalami keterlambatan karena satu guru hubin harus mengurus satu jurusan kelas 11 yang jumlah rata-ratanya 97 siswa.

Agenda harian prakerin adalah kegiatan siswa di tempat prakerin yang ditulis dalam buku agenda, pemberian buku agenda harian tidak terlalu efektif karena minimnya monitoring. Bagian monitoring dua minggu sekali mendatangi perusahaan untuk mengecek agenda harian siswa.

Proses pengolahan nilai diambil dari penilaian pembimbing perusahaan dan hasil sidang laporan, dirasa masih kurang efektif. Data nilai yang ada pada lembar penilaian akan direkap kembali oleh guru hubin ke worksheet sehingga harus kerja dua kali.

Penelitian terdahulu pada tahun 2014, Analisa dan Perancangan Sistem Infomrasi Praktek Kerja Lapangan di Instansi/Perusahaan. Penelitian tersebut membahas mengenai pengelolaan kegiatan pendaftaran, pelaksanaan, pelaporan dan penilaian peserta praktek kerja lapangan [1]. Penelitian serupa juga dilakukan oleh Abdul Gani dan Wire Bagye dengan judul Sistem Informasi Praktek Kerja Industri Pada SMK Islam SIrajul Huda Paok Depok, tentang pengelolaan laporan kegiatan prakerin, jadwal kunjungan guru pembimbing, dan informasi kapan berakhirnya kegiatan prakerin [2]. Penelitian Rancang Bangun Sistem Informasi Praktek Kerja Lapangan Terintegrasi Menggunakan Webservice berfokus pada penugasan dosen pendamping praktek kerja lapangan, monitoring proses praktek kerja lapangan, dan laporan hasil praktek kerja lapangan [3]. Sementara itu penelitian yang dilakukan pada tahun 2019, Analisa dan Perancangan Sistem Informasi Praktek Kerja Industri Menggunakan AHP, dirancang untuk melakukan monitoring dan manajemen kegiatan prakerin [4]. Sistem yang akan dirancang pada penelitian ini berfokus pada pendaftaran, monitoring prakerin, pelaporan dan penilaian prakerin.

\section{Kajian Pustaka}

2.1 Sistem

Sistem merupakan kumpulan komponen fisik dan non fisik yang saling berhubungan dan bekerja sama dengan harmonis untuk dapat mencapai tujuan tertentu [5][6].

2.2 Informasi

Informasi adalah data yang telah diolah menjadi bentuk yang bermanfaat bagi yangn menerimanya [7].

2.3 Sistem Informasi

Sistem informasi merupakan cara-cara yang diorganisasi untuk mengumpulkan, memasukkan, memproses dan menyimpan data agar organisasi dapat menghasilkan informasi dan mencapai tujuan [8][9]. 


\subsection{Prakerin}

Prakerin (Praktek Kerja Industri) adalah kegiatan terjun ke dunia industri sesuai bidangnya bertujuan untuk sebuah pengalaman agar lulusan SMK siap kerja.

\section{Metode Penelitian}

Metode penelitian merupakan sekumpulan peraturan, kegiatan dan prosedur yang dilakukan secara ilmiah untuk memperoleh data dengan kegunaan dan tujuan tertentu. Metode penelitian terdiri dari perumusan masalah, menentukan metode dan pengembangan sistem, merancang sistem dengan menentukan alat bantu perancangan, membuat perangkat lunak dan diakhiri dengan dokumentasi.

\subsection{Metode Pengumpulan Data}

Metode pengumpulan data ialah cara penulis dalam mendapatkan data yang diperlukan untuk penelitian. Terdapat 2 sumber data ialah sumber data sekunder dan primer. Untuk sumber data primer yaitu dengan observasi maupun wawancara dan sumber data sekunder yaitu dengan menggunakan buku maupun internet.

\subsection{Metode Pendekatan Sistem}

Metode pendekatan sistem yang akan digunakan dalam penelitian ini adalah pendekatan terstruktur. Pada dasarnya, pendekatan terstruktur mencoba menyediakan tambahan alat dan teknik bagi analis sistem untuk mengembangkan sistem selain mengikuti siklus hidup sistem.

\subsection{Metode Pengembangan Sistem}

Metode Waterfall adalah pengembangan proses model air terjun seperti terlihat pada gambar 1. Metode waterfall memiliki 5 fase, yaitu Requirement, Design, Implementation, Verification, Maintenance.

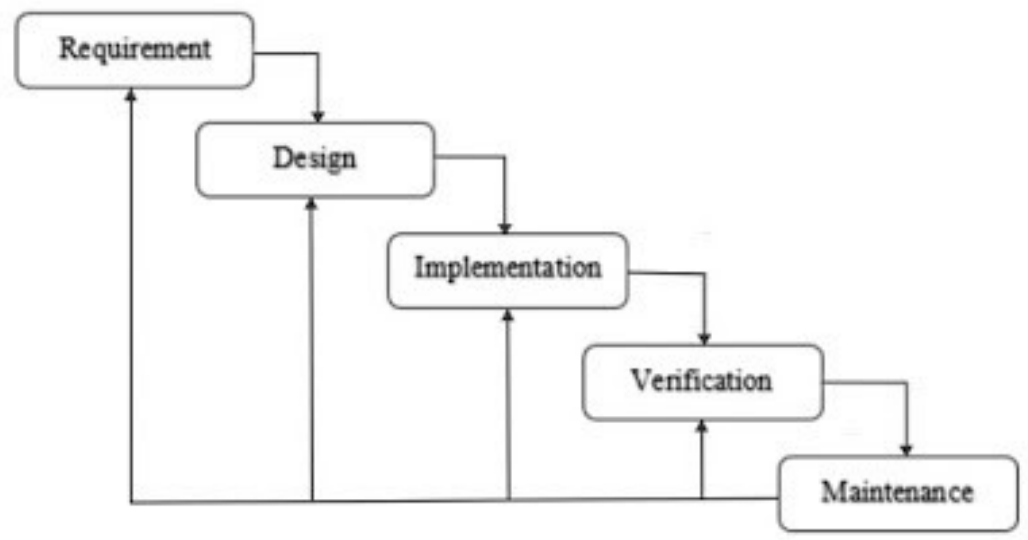

Gambar 1 Metode Waterfall

Metode ini dibagi menjadi fase berurutan, dengan beberapa tumpang tindih dan splashback dapat diterima antara fase. Penekanannya adalah pada perencanaan, jadwal waktu, tanggal target, anggaran dan implementasi seluruh sistem pada satu waktu. Kontrol yang ketat dipertahankan selama umur proyek melalui dokumentasi tertulis dan 
persetujuan / penandatanganan oleh pengguna dan manajemen teknologi informasi yang terjadi pada akhir sebagian besar fase sebelum memulai fase berikutnya [10].

\subsection{Metode Pengujian Sistem}

Dalam penelitian ini penulis menggunakan metode pendekatan black-box testing. Black-box testing merupakan pengujian yang dilakukan dengan hanya mengamati hasil eksekusi melalui data yang diuji dan memeriksa fungsional perangkat lunak.

\section{Hasil dan Pembahasan}

\subsection{Perancangan Sistem}

Sistem yang dirancang digambarkan menggunakan diagram konteks dan DFD seperti pada gambar 2 dan gambar 3 .

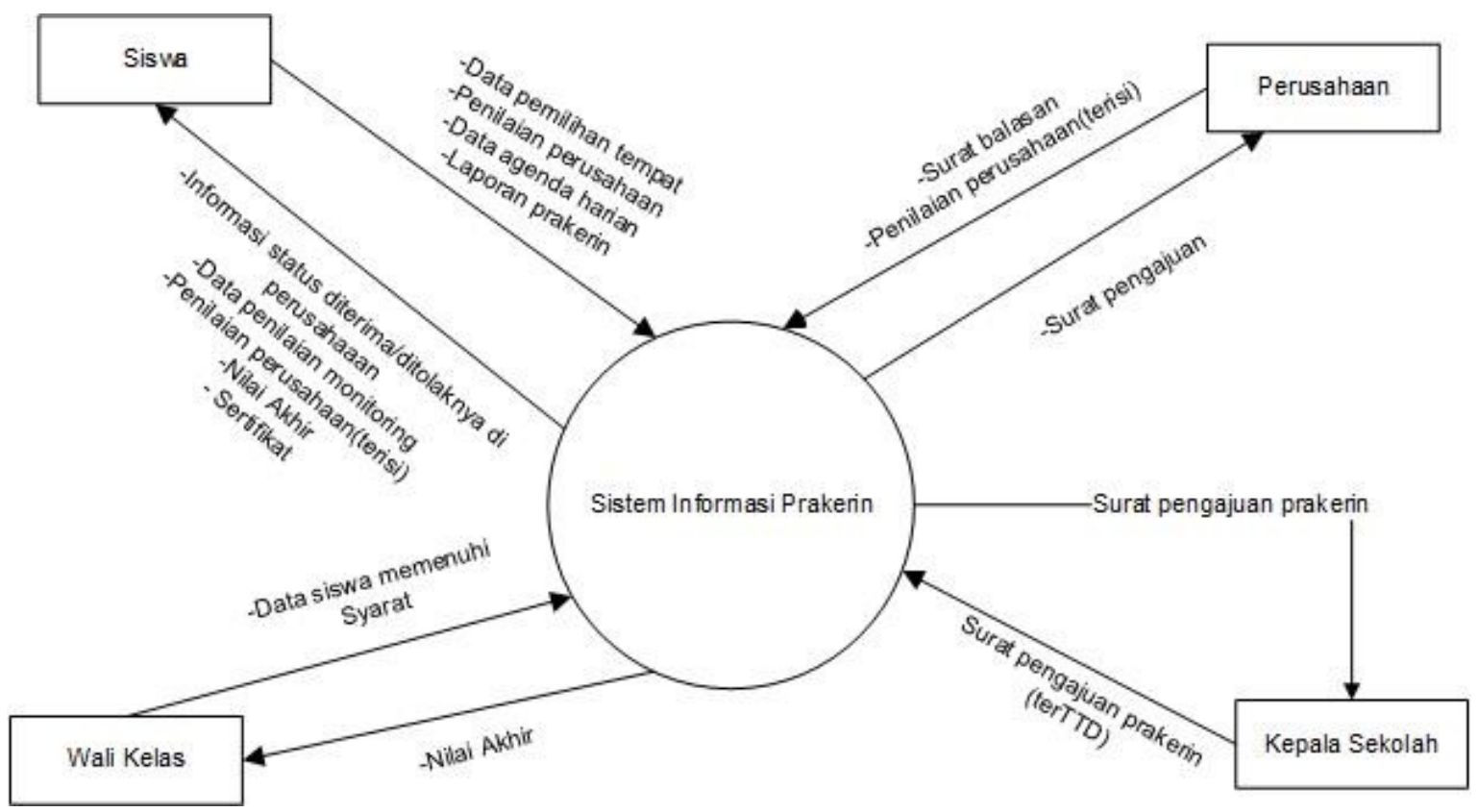

Gambar 2 Diagram konteks yang diusulkan

Entintas yang terlibat, yaitu siswa, perusahaan, wali kelas dan kepala sekolah. Sementara itu detail proses yang terdapat dalam Sistem Informasi Praktek Kerja Industri tergambar pada DFD gambar 3. Pada gambar 2, dapat terlihat pula data yang masuk ke dalam sistem dan keluar dari sistem. 


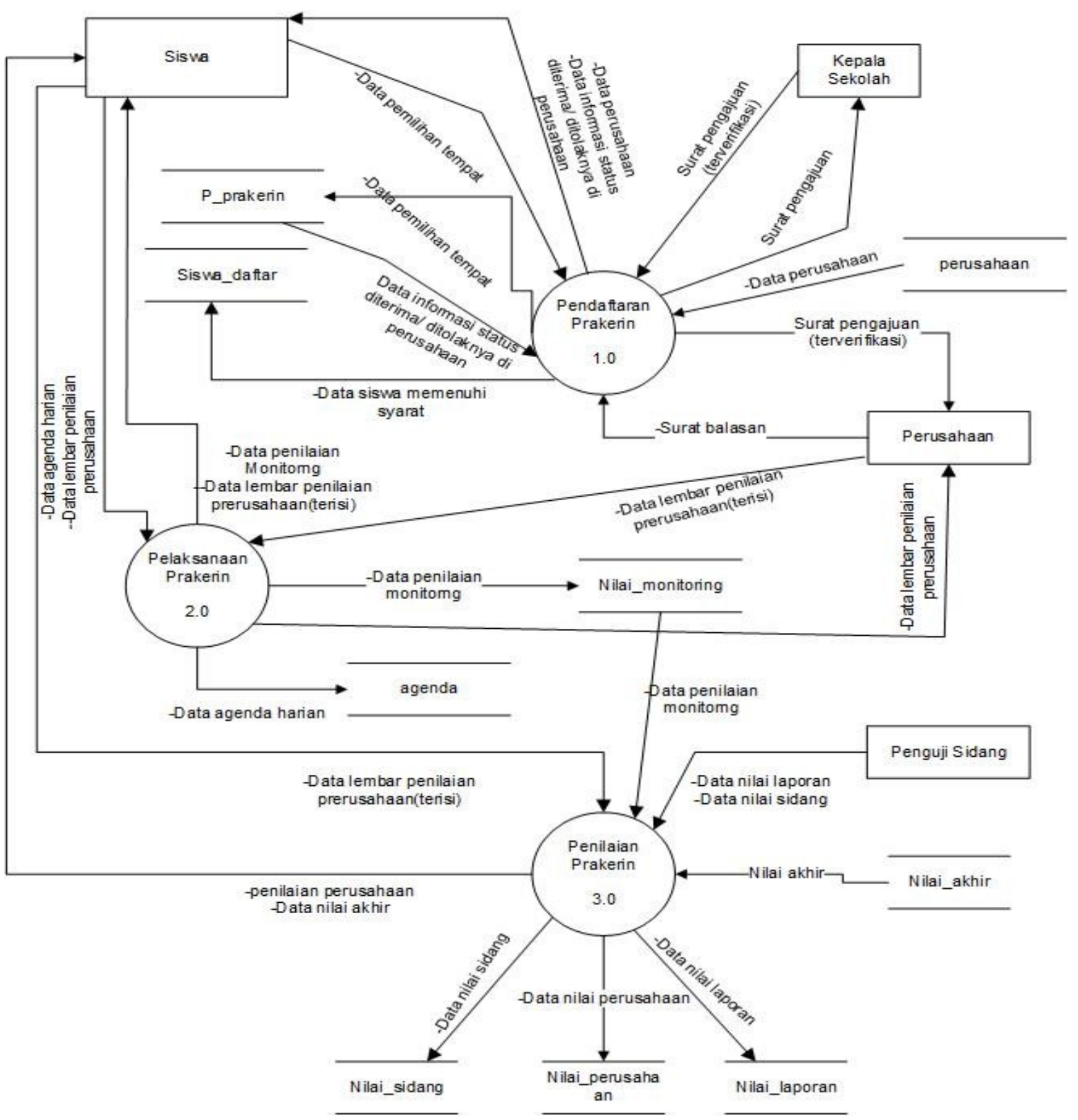

Gambar 3 DFD Level 1 yang diusulkan

Pada DFD level 1, beberapa proses yang ditangani dalam sistem informasi praktek kerja industri, yaitu pendaftaran prakerin, pelaksanaan prakerin, dan penilaian prakerin. Siswa dapat melakukan pendaftaran prakerin melalui sistem serta dapat memilih perusahaan tempatnya melakukan prakerin. Pada proses pelaksanaan, aktivitas harian siswa dapat dipantau oleh hubin melalui sistem dan proses penilaian pun dapat dilakukan dengan input langsung melalui sistem oleh penguji sidang.

Setelah merancang sistem menggunakan DFD, data yang mengalir pada DFD kemudian dirumuskan dalam kamus data dan dinormalisasikan. Kemudian digambarkan dengan relasi tabel seperti pada gambar 4 sehingga dapat terlihat hubungan antar tabel. 


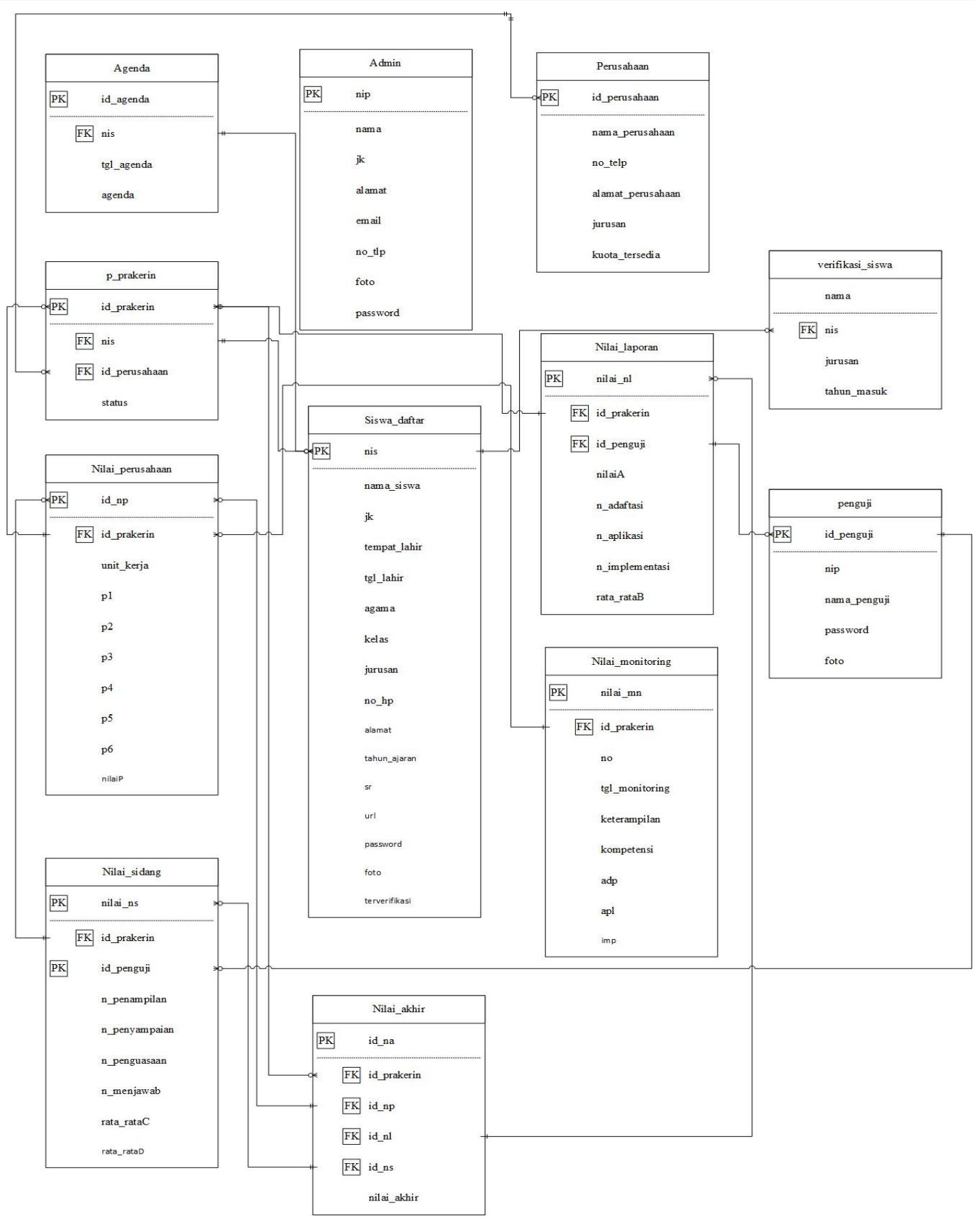

Gambar 4 Relasi tabel

\subsection{Implementasi Antarmuka}

Implementasi antarmuka yaitu implementasi dari tampilan program menjadi tampilan antarmuka aplikasi pengguna. Berikut implementasi antarmuka Sistem Informasi Praktek kerja industri :

\subsubsection{Form Login:}

Sebelum dapat menggunakan sistem informasi prakein, user harus login terlebih dahulu dengan memasukkan username dan password (terlihat pada gambar 5). 


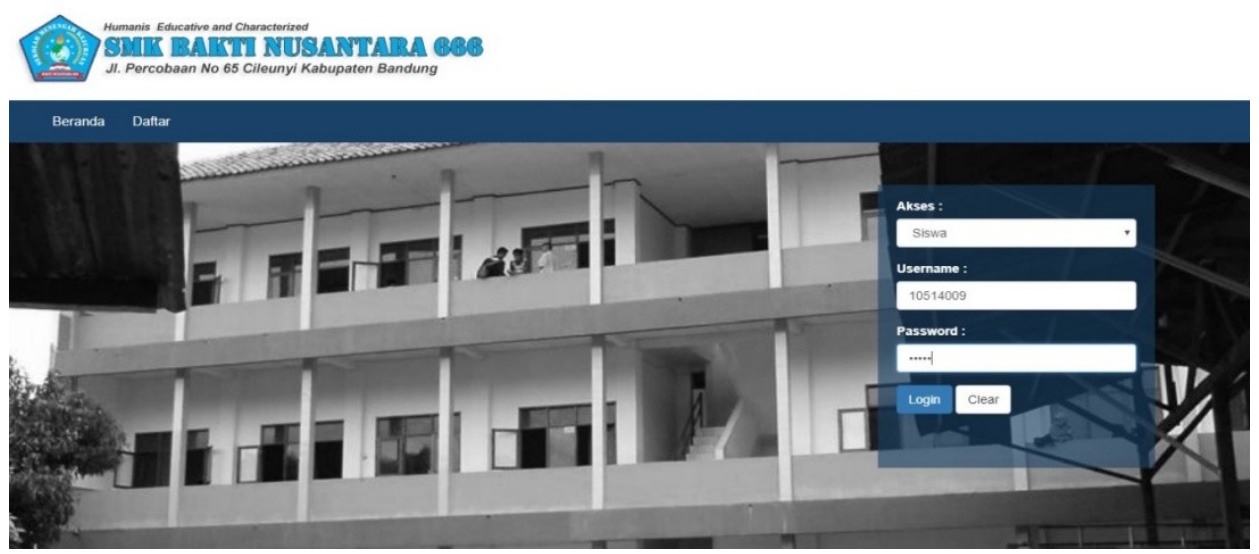

Gambar 5 Form Login

\subsubsection{Halaman Daftar Siswa Prakerin}

Pendaftaran siswa yang akan mengikuti prakerin dapat dilakukan pada form pendaftaran prakein pada gambar 6. Beberapa data yang perlu dimasukkan diantaranya NIS, data diri siswa, dan perusahaan yang hendak dipilih sebagai lokasi prakerin.

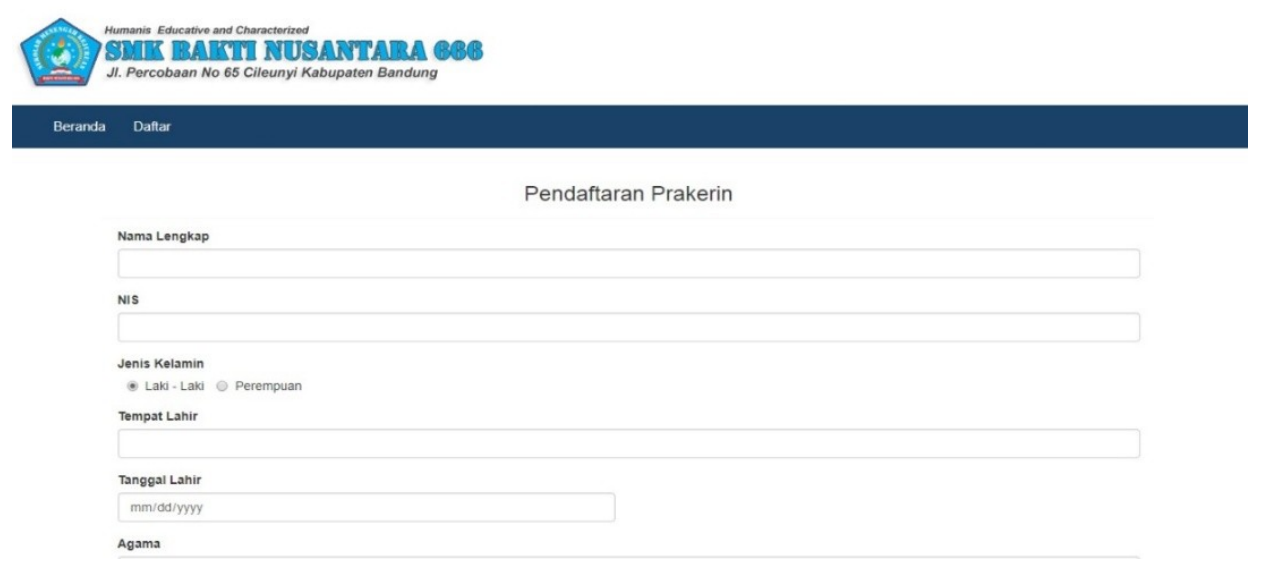

\section{Gambar 6 Form Pendaftaran Prakerin}

\subsubsection{Halaman Pemilihan Perusahaan Oleh Siswa}

Pada halaman ini guru hubin dapat melihat jumlah siswa yang memilih masingmasing perusahaan yang akan dijadikan sebagai lokasi prakerin. Guru hubin juga dapat melihat alokasi yang masih tersedia dari setiap perusahaan seperti pada gambar 7 .
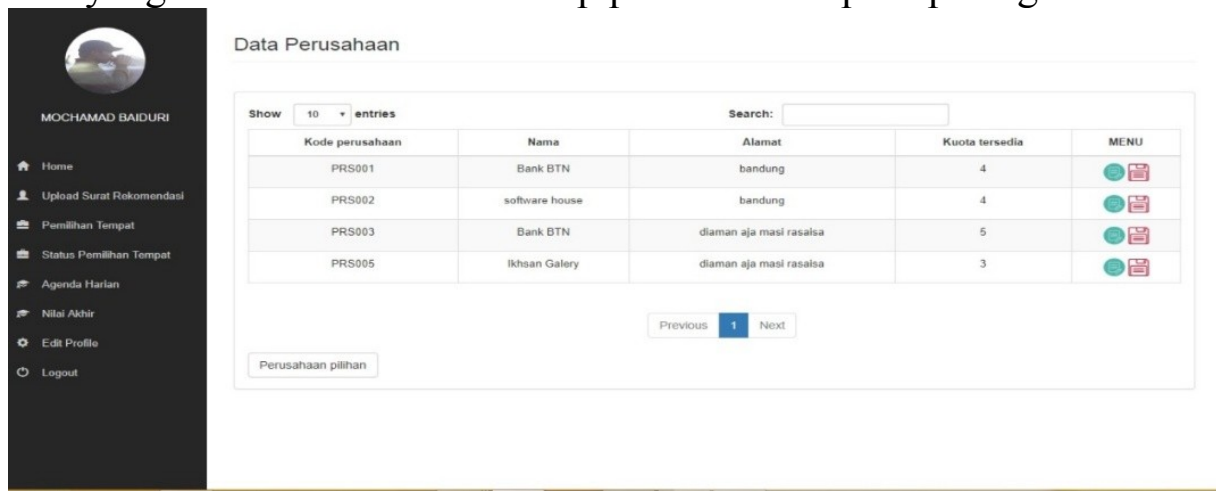

Gambar 7 Form Data Perusahaan 


\subsubsection{Halaman Tampil Nilai Akhir Siswa}

Adapun halaman yang menampilkan bilai akhir prakerin siswa seperti pada gambar 8. Siswa dapat melihat komposisi nilai, besaran masing-masing nilai, serta rumus dari mana nilai akhir didapatkan.
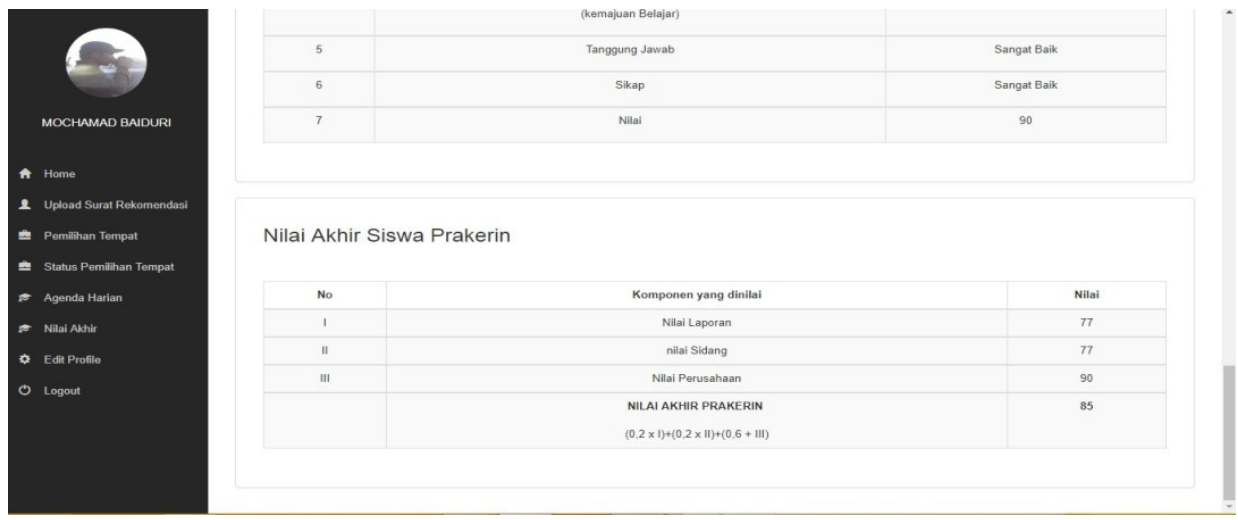

Gambar 8 Nilai Prakerin

\subsubsection{Halaman Penilaian Oleh Penguji}

Setelah kegiatan prakerin selesai, siswa akan membuat laporan akhir. Laporan akhir akan disidangkan dan diuji oleh guru penguji. Guru penguji kemudian akan memasukkan nilai ke dalam sistem informasi praktek kerja industri, terlihat pada gambar 9 .
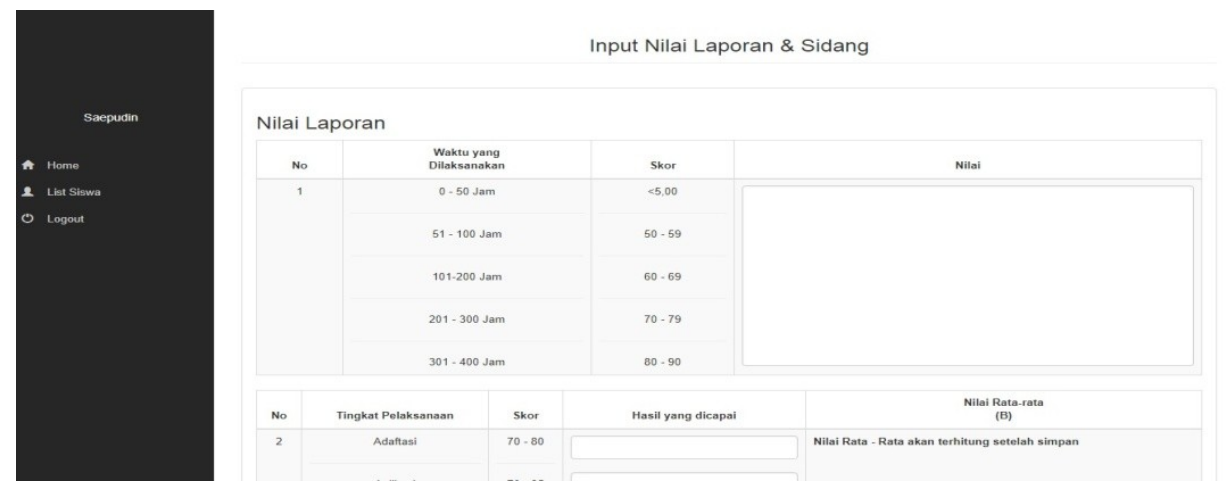

Gambar 9 Form Penilaian

Dengan sistem informasi praktek kerja industri, guru penguji cukup memasukkan besaran nilai setiap komposisi nilai akhir prakerin. Sistem akan secara otomatis menghitung nilai akhir dan guru hubin dapat mencetak nilai akhir tersebut.

\subsection{Rancangan Output}

Beberapa output yang dihasilkan dari sistem informasi praktek kerja industri, yaitu:

\subsubsection{Surat Permohonan Prakerin}

Pendaftaran prakerin yang sudah disetujui akan menghasilkan surat pengajuan prakerin, dimana rancangannya seperti pada gambar 10 . 


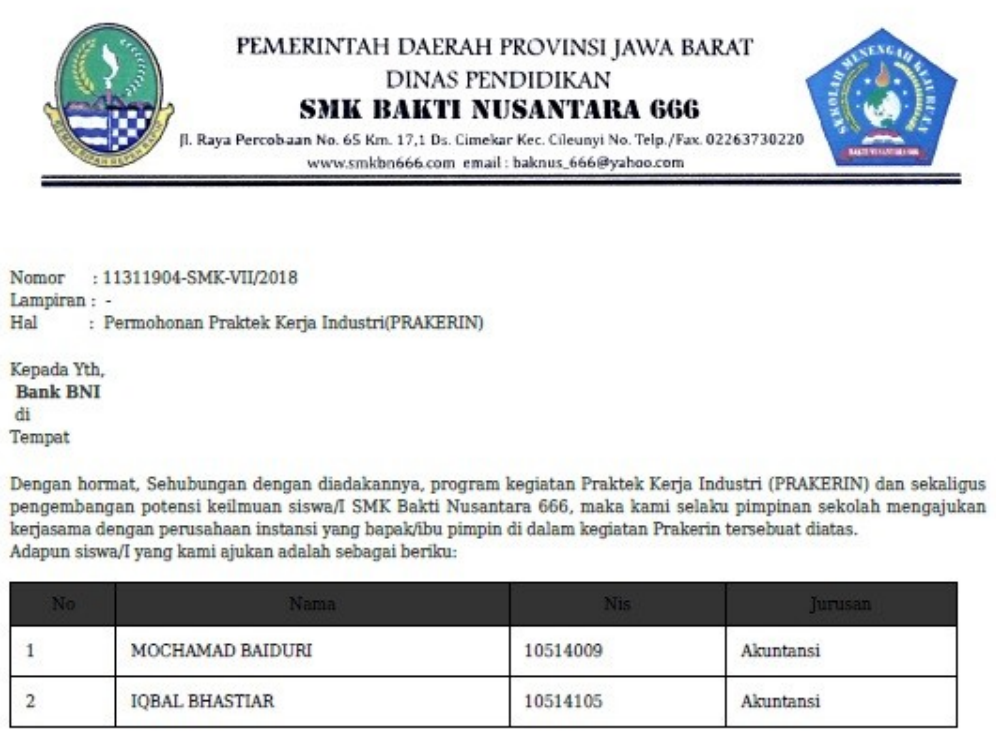

Permohonan pengajuan pelaksanaan kegiatan Prakerin dimulai dari bulan januari 2019 sampai April 2019 selama 3 bulan.

Demikian surat pengajuan ini kami sampaikan, segala perhatian dan kerjasamanya kami ucapkan terima kasih.

$$
\begin{array}{cc}
\text { Mengetahui, } & \text { Kepala Pelaksana } \\
\text { Kepala Sekolah } & \text { Praktek Kerja Industri }
\end{array}
$$

Deni Danis Suara, S.T,M.Kom $\quad$ Pravoga Eka Chandra, S.T

\section{Gambar 10 Surat Permohonan Prakerin}

Surat ini akan diserahkan kepada perusahaan. Dalam surat tercantum nama siswa yang hendak melakukan prakerin di perusahaan dan lama prakerin dilaksanakan.

\subsubsection{Nilai Akhir Prakerin}

Berikut adalah rancangan nilai akhir prakerin seperti pada gambar 11. 


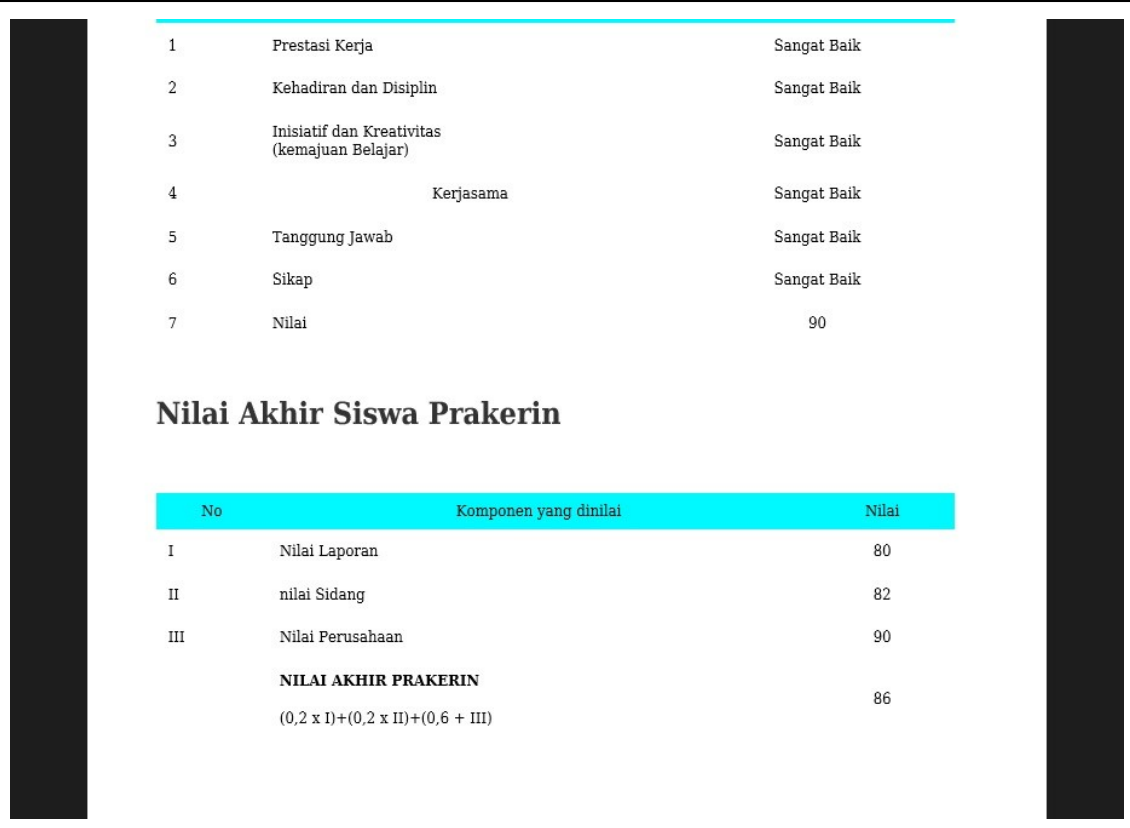

\section{Gambar 11 Nilai Akhir Prakerin}

\subsection{Pengujian}

Pengujian yang dilakukan menggunakan metode black box. Metode black box digunakan untuk menguji fungsionalitas sistem. Pengujian dilakukan pada setiap form yang telah dirancang.

Pengujian form login seperti pada tabel 1, yaitu pengujian jika data yang dimasukkan benar dan salah.

Tabel 1 Pengujian Form Login

\begin{tabular}{|l|l|l|l|}
\hline \multicolumn{5}{|c|}{ Kasus dan hasil uji (Data Benar) } \\
\hline Data Masukan & Yang Diharapkan & \multicolumn{1}{|c|}{ Pengamatan } & Kesimpulan \\
\hline $\begin{array}{l}\text { Contoh masukan } \\
\text { Username : dia } \\
\text { Password : dia }\end{array}$ & $\begin{array}{l}\text { Mengisikan data } \\
\text { login yang sudah } \\
\text { terdaftar. }\end{array}$ & $\begin{array}{l}\text { Data login benar dan akan } \\
\text { masuk ke masing-masing } \\
\text { interface yang telah } \\
\text { ditentukan sesuai dengan data } \\
\text { login. }\end{array}$ & $\begin{array}{l}{[\sqrt{ }] \text { diterima }} \\
{[] \text { ditolak }}\end{array}$ \\
\hline \multicolumn{5}{|c|}{ Kasus dan hasil uji (Data Salah) } \\
\hline $\begin{array}{l}\text { Data Masukan } \\
\begin{array}{l}\text { Username : dia } \\
\text { Password : admin }\end{array}\end{array}$ & $\begin{array}{l}\text { Yang Diharapkan } \\
\text { "Gagal Login, user } \\
\text { tidak terdaftar" }\end{array}$ & $\begin{array}{l}\text { Muncul pesan "Gagal Login, } \\
\text { user tidak terdaftar" }\end{array}$ & $\begin{array}{l}{[\sqrt{ }] \text { diterima }} \\
{[] \text { ditolak }}\end{array}$ \\
\hline
\end{tabular}

Pengujian juga dilakukan pada form pemilihan lokasi prakerin oleh siswa, pada tabel 2 , yaitu dengan kasus siswa memilih tempat untuk pertama kali dan memilih tempat ketika siswa telah melakukannya sebelumnya. 
Tabel 2 Pengujian Pemilihan Lokasi Prakerin

\begin{tabular}{|l|l|l|l|}
\hline \multicolumn{4}{|c|}{ Kasus dan hasil uji (memilih tempat) } \\
\hline Data Masukan & Yang Diharapkan & \multicolumn{1}{|c|}{ Pengamatan } & Kesimpulan \\
\hline $\begin{array}{l}\text { Contoh siswa } \\
\text { memilih tempat }\end{array}$ & $\begin{array}{l}\text { Menghasilkan data } \\
\text { pemilihan tempat }\end{array}$ & $\begin{array}{l}\text { Pemilihan tempat bisa } \\
\text { tersimpan }\end{array}$ & $\begin{array}{l}{[\sqrt{ }] \text { diterima }} \\
{[] \text { ditolak }}\end{array}$ \\
\hline \multicolumn{4}{|c|}{ Kasus dan hasil uji (sudah memilih tempat) } \\
\hline $\begin{array}{l}\text { Data Masukan } \\
\text { telah memilih } \\
\text { tempat }\end{array}$ & $\begin{array}{l}\text { Yang Diharapkan } \\
\text { "Anda telah } \\
\text { memilih } \\
\text { sebelumnya" }\end{array}$ & $\begin{array}{l}\text { Puncul pesan "Anda } \\
\text { telah memilih } \\
\text { sebelumnya" }\end{array}$ & $\begin{array}{l}{[\sqrt{ }] \text { diterima }} \\
{[] \text { ditolak }}\end{array}$ \\
\hline
\end{tabular}

Pengujian selanjutnya pada pengisian agenda harian prakerin yang akan dimonitoring oleh guru hubin. Tabel pengujian dengan kasus mengisi agenda harian untuk pertama kali dan mengisi kembali agenda harian pada hari yang sama, tabel 3.

Tabel 3 Pengujian Pengisian Agenda Harian Prakerin

\begin{tabular}{|l|l|l|l|}
\hline \multicolumn{5}{|c|}{ Kasus dan hasil uji (input agenda harian) } \\
\hline \multicolumn{1}{|c|}{ Data Masukan } & \multicolumn{1}{|c|}{ Yang Diharapkan } & \multicolumn{1}{c|}{ Pengamatan } & Kesimpulan \\
\hline $\begin{array}{l}\text { Contoh siswa } \\
\text { mengisi agenda }\end{array}$ & $\begin{array}{l}\text { Menghasilkan data } \\
\text { agenda harian }\end{array}$ & $\begin{array}{l}\text { Data agenda harian } \\
\text { berhasil disimpan }\end{array}$ & $\begin{array}{l}{[\sqrt{ }] \text { diterima }} \\
{[] \text { ditolak }}\end{array}$ \\
\hline \multicolumn{4}{|c|}{ Kasus dan hasil uji (sudah memilih tempat) } \\
\hline $\begin{array}{l}\text { Data Masukan } \\
\text { mengisi agenda } \\
\text { harian di hari yang } \\
\text { sama }\end{array}$ & $\begin{array}{l}\text { Yang Diharapkan } \\
\text { ini anda telah } \\
\text { mengisi agenda"Hari }\end{array}$ & $\begin{array}{l}\text { Muncul pesan "Hari ini } \\
\text { anda telah mengisi } \\
\text { agenda" }\end{array}$ & $\begin{array}{l}{[\sqrt{ }] \text { diterima }} \\
{[\text { ditolak }}\end{array}$ \\
\hline
\end{tabular}

Pada kasus ini, siswa yang telah mengisi agenda harian prakerin, tidak dapat mengisi kembali di hari yang sama. Agenda harian hanya dapat diisi satu kali per hari.

\subsection{Implementasi Perangkat Lunak dan Perangkat Keras}

Untuk dapat menerapkan sistem infomrasi praktek kerja industri, diperlukan spesifikasi dasar dalam perangkat lunak dan keras yang harus dimiliki.

\subsubsection{Implementasi Perangkat Lunak}

Detail perangkat lunak yang digunakan dalam perancangan sistem informasi praktek kerja industri ini, yaitu:

1. Operation System $\quad$ : Microsoft Windows 8.1 
2. Server Basis Data : MySQL

3. Web Server : Apache

4. Bahasa Pemrograman : PHP

5. Web Browser : Google Chrome

\subsubsection{Implementasi Perangkat Keras}

Spesifikasi minimal perangkat keras sistem informasi praktek kerja industri di SMK Bakti Nusantara 666 Cileunyi, yaitu:

$\begin{array}{lll}\text { 1. } & \text { Prosesor } & \text { : AMD A8 } \\ \text { 2. } & \text { RAM } & \text { : 4 GB DDR3 } \\ \text { 3. } & \text { Hard Disk } & \text { : 500GB HDD } \\ \text { 4. } & \text { Monitor } & \text { : LED 11.6" HD } \\ \text { 5. } & \text { Mouse } & \\ \text { 6. } & \text { Keyboard } & \\ \text { 7. } & \text { Printer } & \end{array}$

\section{Kesimpulan}

Perancangan Sistem Informasi Praktek Kerja Industri di SMK Bakti Nusantara 666 Cileunyi telah dapat membantu siswa dan guru hubin dalam pendaftaran dan monitoring prakerin. Sementara itu, sistem informasi ini juga dapat membantu guru penguji dan guru hubin dalam mengelola nilai akhir prakerin.

\section{Daftar Pustaka}

[1] M. Arifin, "Analisa dan Perancangan Sistem Informasi Praktek Kerja Lapangan pada Instansi/Perusahaan," SIMETRIS Jurnal Teknik Industri, Mesin, Elektro dan Ilmu Komputer, Vol. 5, No. 1, pp. 49-56, 2014.

[2] A. Gani and W. Bagye, "Sistem Informasi Praktek Kerja Industri Pada SMK Islam Sirajul Huda Paok Depok," MISI Jurnal Manajemen Informastika \& Sistem Infomasi, Vol. 1, No. 1, pp 52-56, 2018.

[3] T. Andriyanto and R. A. R, "Rancang Bangun Sistem Informasi Praktek Kerja Lapangan Terintegrasi Menggunakan Web Service," SIMETRIS Jurnal Teknik Industri, Mesin, Elektro dan Ilmu Komputer, Vol. 7, No. 2, pp 551-558, 2016.

[4] F. S. Pradana, "Analisa dan Perancangan Sistem Informasi Praktek Kerja Industri Menggunakan AHP," JUST IT Jurnal Sistem Informasi, Teknologi Informasi dan Komputer, Vol. 10, No. 1, pp 72-77, 2019.

[5] B. Soeherman and M. Pinontoan, Designing Information System, Jakarta: Elex Media Komputindo, 2008.

[6] A. Susanto, Sistem Informasi Akuntansi, Bandung: Lingga Jaya, 2013.

[7] A. Mulyanto, Sistem Informasi Konsep dan Aplikasi, Yogyakarta: Pustaka Pelajar, 2009.

[8] K. Krismiaji, Sistem Informasi Akuntansi. Yogyakarta: Unit. Penerbit dan Percetakan Sekolah Tinggi Ilmu YKPN, 2010.

[9] E. Eliana and M. D. Rahmatya, "Perancangan Sistem Informasi Administrasi pada Pondok Pesantren Pembangunan Sumur Bandung," Jurnal Teknologid dan Informasi 
(JATI), vol. 9, no. 1, pp. 1-11, 2019. Available: https://ojs.unikom.ac.id/index.php/jati/article/view/1330.

[10] A. Saxena and P. Upadhyay, "Waterfall vs. Prototype: Comparative Study of SDLC. Imperial Journal of Interdiciplinary Research," IJIR, Vol. 2, No. 6, pp. 1012-1015, 2016. 